\title{
THERMAL LARGE EDDY SIMULATION WITH SENSIBLE HEAT FLUX DISTRIBUTION FROM VARIOUS 3D BUILDING GEOMETRIES
}

\author{
Mohammed BAKKALI ${ }^{1}$, Atsushi INAGAKI ${ }^{2}$, Yasunobu ASHIE ${ }^{3}$, Yuma YOSHIDA ${ }^{4}$, \\ Manabu KANDA ${ }^{5}$ and Siegfried RAASCH 6 \\ ${ }^{1}$ Member of JSCE, Dr. Res. of Eng., Researcher, Dept. of International Development Engineering, Tokyo Institute of \\ Technology (Ookayama 2-12-1, Meguro-ku, Tokyo 152, Japan) \\ ${ }^{2}$ Member of JSCE, Dr. of Eng., Associate Professor, Dept. of International Development Engineering, Tokyo \\ Institute of Technology (Ookayama 2-12-1, Meguro-ku, Tokyo 152, Japan) \\ ${ }^{3}$ Dr. of Eng., Head, Dept. of Standards and Accreditation System Division, NILIM (Tachihara 1, Tsukuba City, \\ Ibaraki Prefecture 305, Japan) \\ ${ }^{4}$ M. Eng., Student, Dept. of International Development Engineering, Tokyo Institute of Technology (Ookayama \\ 2-12-1, Meguro-ku, Tokyo 152, Japan) \\ ${ }^{5}$ Member of JSCE, Dr. of Eng., Professor, Dept. of International Development Engineering, Tokyo Institute of \\ Technology (Ookayama 2-12-1, Meguro-ku, Tokyo 152, Japan) \\ ${ }^{6}$ Dr. of Eng., Professor, Institute for Meteorology and Climatology, Leibniz University of Hanover (Herrenhäuser \\ Strasse 2, Hannover 30419, Germany)
}

\begin{abstract}
Large Eddy Simulation (LES) with realistic three-dimensional building geometries have been performed for both neutral conditions and unstable thermal conditions. Parallelized Large-Eddy Simulation (PALM) has been implemented for LES modelling. Heterogeneous three-dimensional sensible heat fluxes over impervious urban surfaces at five metres resolution in Shinjuku have been calculated by an urban outdoor-indoor multi-patch energy balance model (3D-City Irradiance). This can calculate sophisticated radiation exchange processes. Then, these values have been inputted into PALM by the setting of Neumann boundary conditions. The effect of buoyancy from surface heating on turbulent structures within the urban atmospheric boundary layer and the urban canopy layer has been generally investigated. Moreover, special attention has been paid to streaky mechanical and thermal turbulent structures above high-rise buildings, which have been considerably altered.
\end{abstract}

Key Words: LES, building- geometries, heterogeneous-three-dimensional-sensible-heat-fluxes, imperviousurban-surfaces, buoyancy

\section{INTRODUCTION}

Large eddy simulation (LES) is considered to be one of the most powerful numerical Smagorinsky based models in terms of its relevance in investigating detailed turbulent flow structures. In the field of urban meteorology, LES has been mainly applied for neutrally stratified flows around simple idealised building arrays ${ }^{122}$ in the same way as other models ${ }^{344)}$. LES with realistic three-dimensional building arrangements has been recently made possible ${ }^{5) 6}$ due to significant improvements in high performance computing. However, the inclusion of realistic sensible heat flux distributions from three-dimensional urban facets into high-resolution LES is still uncommon ${ }^{778)}$, although measurements ${ }^{9)}$ can enable this. Sühring et al. studied the effect of one-dimensional stripe-like surface heat flux heterogeneities on the mixed layer top entrainment ${ }^{10)}$. The profiles of sensible heat flux and the temporal evolution of the depth of the boundary layer revealed a decreased entrainment for heat fluxes with small amplitudes and an increased entrainment for heat fluxes with large amplitudes compared to the homogeneously heated mixed layer. 

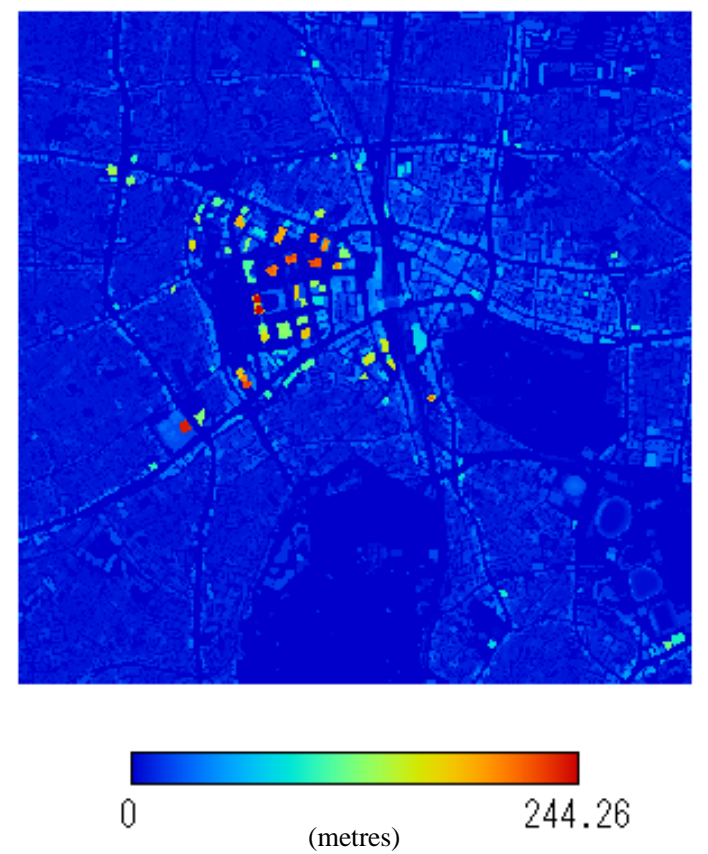

Fig.1 Building height distribution within computational domain.

In addition, Yaghoobian et al. looked at the impact of diurnal variations of the heat fluxes for two clear summer days that differ in atmospheric instability on the fluid flow and air temperature distribution in idealised street canyons ${ }^{11)}$. Furthermore, Maronga et al. calculated the effect of surface heterogeneity on the structure parameters of potential temperature and specific humidity in the convective boundary layer ${ }^{12)}$ (CBL) through the implementation of the kilometre-scale heterogeneous land use distribution as observed from experiments and then prescribed at the surface of the LES model in order to simulate a realistic CBL development from early morning until early afternoon. The surface patches are irregularly distributed and represent different land use types that exhibit different roughness, sensible and latent heat fluxes conditions near surface.

\section{OBJECTIVE}

The integrated effects of mechanical and thermal turbulence on urban weather dynamics are important An urban LES model has been implemented with three-dimensional heterogeneous sensible heat flux at high resolution similar to real conditions. So far, this numerical method has not been implemented yet. The comparison of combined 'real' buoyancy-wind shear effects in thermally stratified conditions against 'ideal' effects or merely wind shear effects in neutral conditions on drag and turbulent flows is useful. The patterns, intensity, location and size of streaky turbulent organized structures, local turbulent mixing and horizontal convective rolls can therefore be depicted.
Table 1 Computational setting, V3 and V10 explanation (table2).

\begin{tabular}{|c|c|}
\hline Domain size & $4000 \mathrm{~m} \times 4000 \mathrm{~m} \times 4619 \mathrm{~m}$ \\
\hline Grid size & $\begin{array}{c}5 \mathrm{~m} \times 5 \mathrm{~m} \times 5 \mathrm{~m}(\mathrm{z}<1750 \mathrm{~m}) \\
\text { Note: } \mathrm{z}>1750 \mathrm{z} \text {-direction grid } \\
\text { size is stretched }\end{array}$ \\
\hline Initial wind velocity & $3.0 \mathrm{~m} \mathrm{~s}^{-1}, 10.0 \mathrm{~m} . \mathrm{s}^{-1}$ \\
\hline $\begin{array}{c}\text { Inputted sensible heat } \\
\text { flux }\end{array}$ & $0.186 \mathrm{~K} \cdot \mathrm{m}^{-1}$ \\
\hline Calculation date & 4th June $201312 \mathrm{pm}$ \\
\hline Boundary conditions & Cyclic (x, y) \\
Slip (top) \\
Non-Slip (Bottom)
\end{tabular}

\section{METHODOLOGY}

In this study, the Parallelized Large-Eddy Simulation ${ }^{13)}$ model (PALM) has been implemented with realistic three-dimensional building geometries. This has been performed for both neutral conditions and unstable thermal conditions. Three-dimensional sensible heat flux distributions over rigid urban surfaces especially over buildings have been calculated by means of an urban outdoor-indoor multi-patch energy balance model (3D-City Irradiance model) $)^{1415)}$ with the assumption of a constant heat transfer coefficient between the constituent surfaces and the air adjacent to them. In addition to complex conductive heat exchanges, this model is able to calculate three-dimensional multi-beam radiation exchange processes within and above urban canyons. Then, values from sensible heat flux have been inputted into PALM through Neumann boundary conditions. In order to measure the effect of heterogeneous sensible heat flux distributions from different urban surfaces on the turbulent flow field in detail, three additional case studies have been run by using LES modelling. The first case has been calculated under neutral conditions and the two others under unstable thermal conditions where the total sensible heat flux over the domain has been kept unchanged $\left(0.186 \mathrm{~K}_{\mathrm{m} \mathrm{s}} \mathrm{s}^{-1}\right)$ and similar to output results from the 3D-City Irradiance model. However, different sensible heat flux distributions have been implemented. In one case, constant sensible heat flux over building roofs and over urban ground surfaces was implemented and in the other case constant sensible heat flux over sunlit urban surfaces was exclusively incorporated.

\section{NUMERICAL SETTINGS}

Shinjuku district in central Tokyo was chosen for this research. As shown in Fig.1, this district represents one of major urban centres with a diverse urban fabric. In Table 1, the numerical settings 

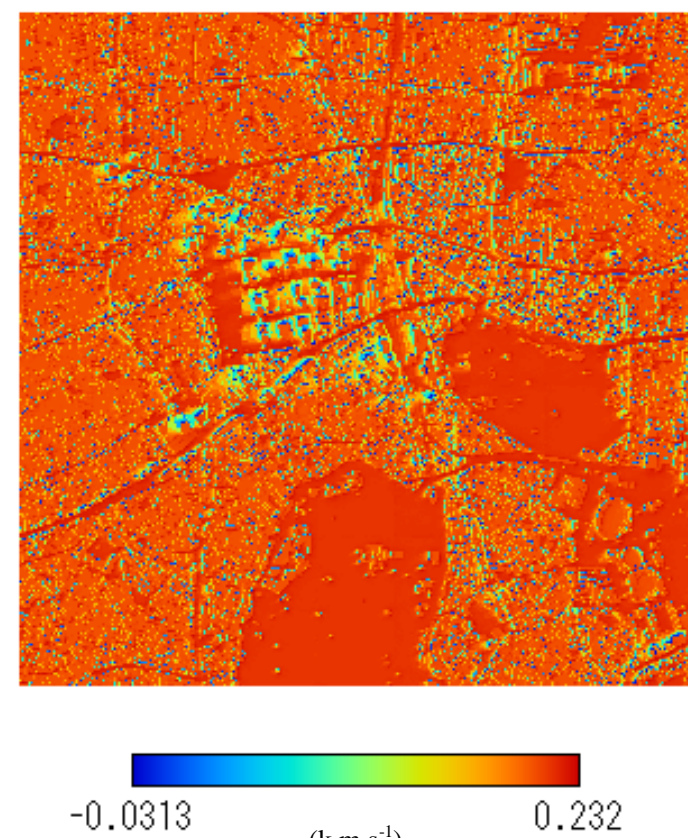

$\left(\mathrm{k} . \mathrm{m} \cdot \mathrm{s}^{-1}\right)$
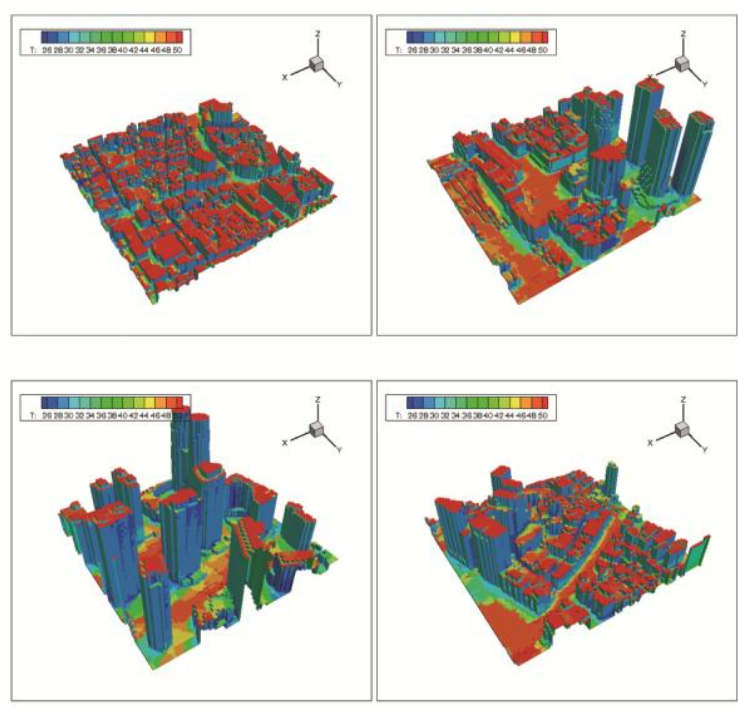

T: 26283032343638404244464850 $\left({ }^{\circ} \mathrm{C}\right)$

Fig.2 Kinematic sensible heat flux distribution at horizontal urban surfaces calculated by 3D-City Irradiance (left) and a few examples of surface temperature distributions before coupling (right).

Table 2 Simulation cases, initial geostrophic wind velocity $(\mathrm{u})$ at the surface was set at $3 \mathrm{~m} \cdot \mathrm{s}^{-1}(\mathrm{~V} 3)$ and then at $10 \mathrm{~m} \cdot \mathrm{s}^{-1}(\mathrm{~V} 10)$.

\begin{tabular}{|c|c|c|}
\hline Simulation Case & Initial velocity & Sensible heat flux \\
\hline 3D-Rad_v3 & $3 \mathrm{~m} \cdot \mathrm{s}^{-1}$ & Heterogeneous from all urban facets (3D-City Irradiance) \\
\hline Ray-Tra_v3 & $3 \mathrm{~m} \cdot \mathrm{s}^{-1}$ & Homogeneous from sunlit facets \\
\hline Floor-Heat_v3 & $3 \mathrm{~m} \cdot \mathrm{s}^{-1}$ & Homogeneous from roofs and the ground \\
\hline No-Heat_v3 & $3 \mathrm{~m} \cdot \mathrm{s}^{-1}$ & Zero sensible heat \\
\hline 3D-Rad_v10 & $10 \mathrm{~m} \cdot \mathrm{s}^{-1}$ & Heterogeneous from all urban facets (3D-City Irradiance) \\
\hline Ray-Tra_v10 & $10 \mathrm{~m} \cdot \mathrm{s}^{-1}$ & Homogeneous from sunlit facets \\
\hline Floor-Heat_v10 & $10 \mathrm{~m} \cdot \mathrm{s}^{-1}$ & Homogeneous from roofs and the ground \\
\hline No-Heat_v10 & $10 \mathrm{~m} . \mathrm{s}^{-1}$ & Zero sensible heat \\
\hline
\end{tabular}

of LES are shown. Grid size along $\mathrm{z}$ axis is stretched with a factor of 1.08 above $\mathrm{z}=1750 \mathrm{~m}$. Besides low-rise buildings, this area includes many high-rise buildings at the centre of the domain, and open spaces (parks) in southern and eastern areas.

As previously cited, four different LES runs have been performed with two different settings of geostrophic wind velocities at the surface, $3 \mathrm{~m} \mathrm{~s}^{-1}$ and $10 \mathrm{~m} \mathrm{~s}^{-1}$ respectively, see Table 2. First LES run does not consider sensible heat flux into account and it is set as null all over the surfaces (hereafter, No-Heat). Second LES run contains constant sensible heat flux over sunlit urban surfaces exclusively by using Ray Tracing method (hereafter, Ray-Tra). Third LES run contains constant sensible heat flux over horizontal urban surfaces, i.e. building roofs and urban ground surfaces (hereafter, Floor-Heat). In this case, sensible heat flux over the remaining surfaces is null. Finally, the fourth LES run contains realistic sensible heat flux distributions calculated by the 3D-City Irradiance model (hereafter, 3D-Rad), see Fig. 2.

In order to prepare LES boundary conditions for sensible heat flux distribution from all the urban facets of various building geometries, 3D-City-
-Irradiance model has calculated 81 sub-domains following a batch serial calculation method. All together, these sub-domains form the domain of interest. In every sub-domain, output results from a band of 50 metres around the edges were neglected so that calculation errors due to cyclic boundary conditions and tall buildings could be avoided. The simulated time covers 24 hours. However, only the hour 12.00 was inputted. Incoming radiation at that time is most vertical and intense. Every sub-domain is composed of $100 \times 100 \times 100$ meshes. These meshes are made of regular structured grids of five metres resolution. Regarding the scope of this research on the effect of heterogeneous sensible heat flux from building geometries on buoyancy and other turbulent flows, the construction materials have been set uniformly over the domain and they are all concrete-based materials. However, construction layers differ between roofs on one hand and ground and building walls on the other hand so as to keep the settings as 'realistic' as possible over the calculation domain. Effects of other construction materials, windows and air conditioning systems will be the subject of future research. 


\section{RESULTS AND DISCUSSION}

(1) Normalised turbulent statistics in the urban canopy layer

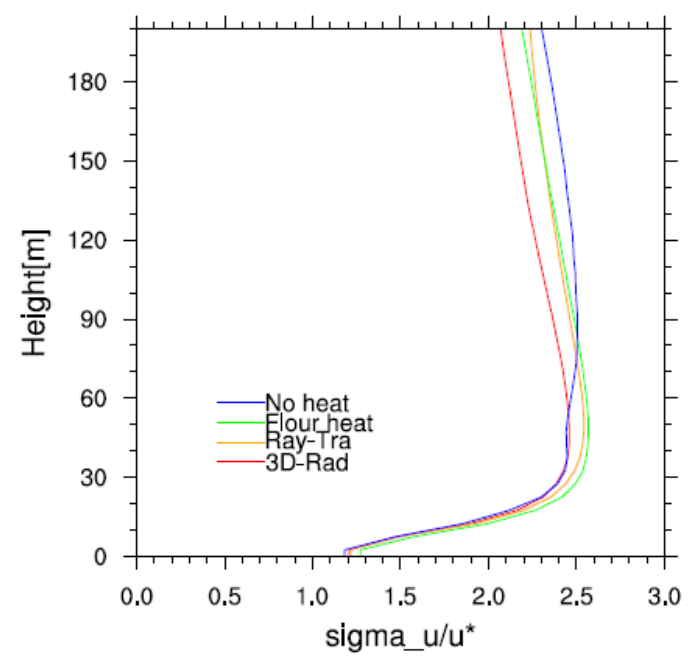

(2) Turbulent field in the urban canopy layer

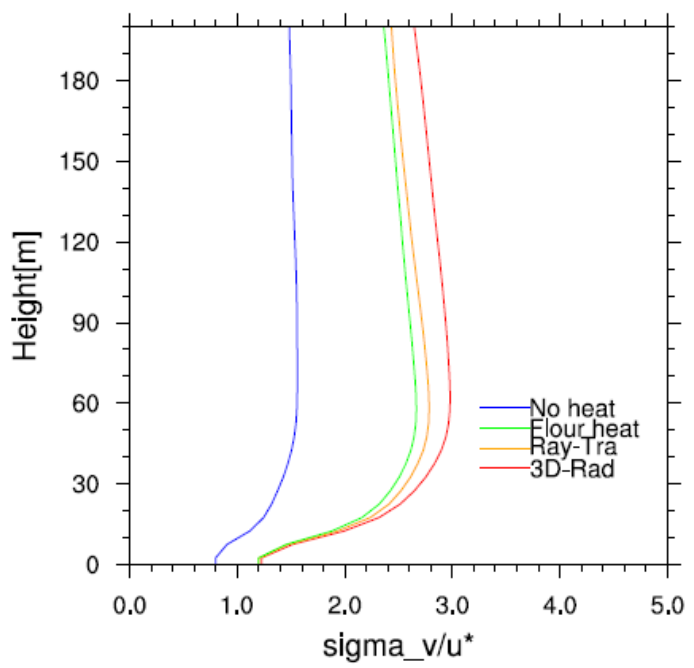

Fig.3 Normalised standard deviation of $\mathrm{u}$ (left) and v (right) velocity fluctuations when initial wind velocity is set to $3 \mathrm{~m} \cdot \mathrm{s}^{-1}$.

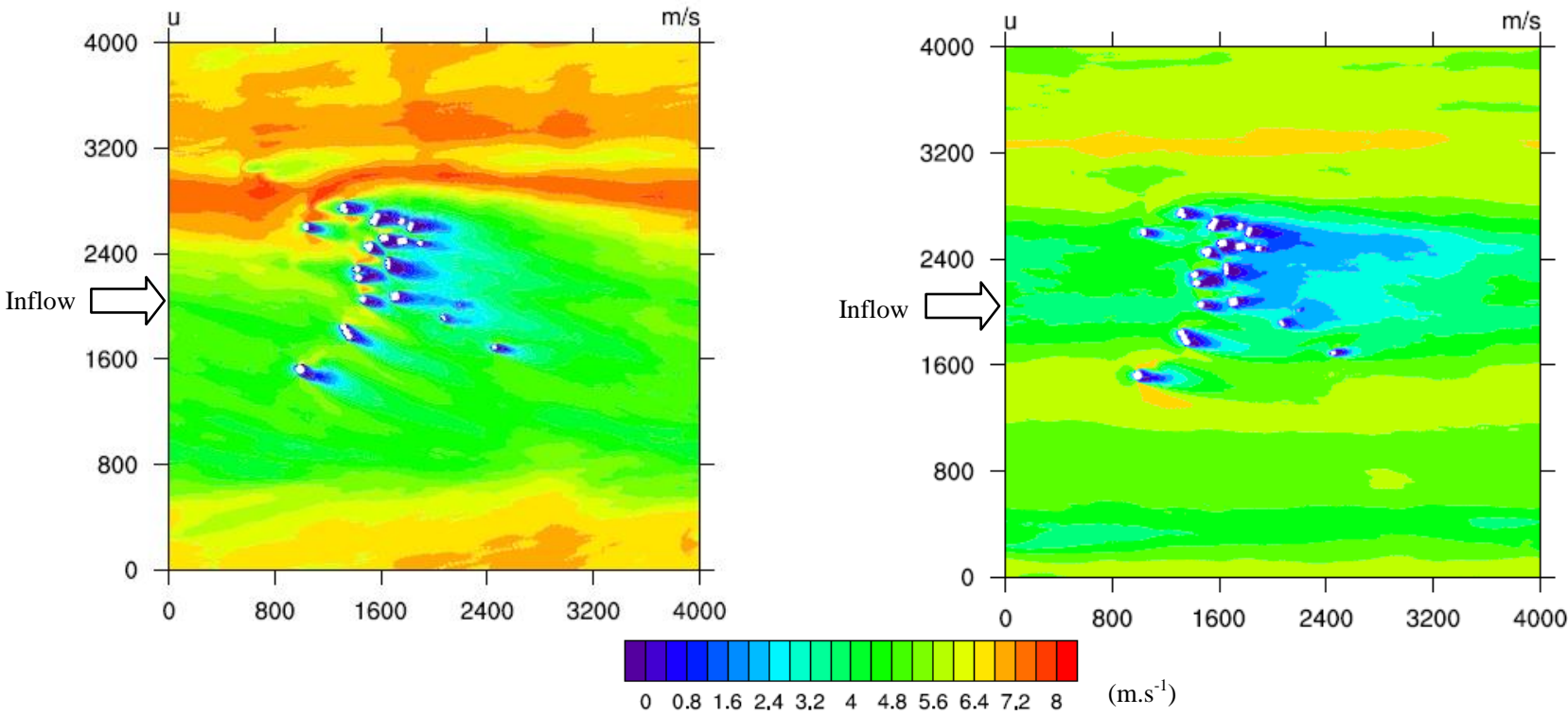

Fig.4 u component at $\mathrm{z}=152.5 \mathrm{~m}$ for 3D-Rad_v10 (left) and No-Heat_v10 (right), the value of (u) was averaged by $30 \mathrm{~min}$.

All three unstable thermal cases have smaller $(\mathrm{u})$ fluctuations and larger (v) fluctuations than the neutral case (Fig.3). The implementation of a constant total sensible heat flux from the constituent urban surfaces does certainly enhance the turbulent mixing in the urban boundary layer. This results in decreasing velocity fluctuations of (u) due to a larger drag especially in the upper level of the urban canopy and increasing velocity fluctuations of (v) due to enhanced lateral turbulent motions. Among these unstable cases, the trends mentioned above are even clearer and well emphasised when realistic sensible heat flux distributions are implemented; see case (3D-Rad_v3). This is undoubtedly due to higher variations of the heterogeneous sensible heat flux.
All over Shinjuku district, the variations of wind velocity component $(\mathrm{u})$ at the height $\mathrm{z}=152.5$ metres have been calculated for the unstable case (3D-Rad_v10) and the neutral case (No-Heat_v10), see Fig. 4. The height's value $\mathrm{z}$ corresponds to the upper third of the urban canopy layer. The cluster composed of high-rise buildings creates slower, wider and deflected streaks under higher wind speeds. The wind velocity fluctuations of $(u)$ between this group of high-rise buildings and surrounding urban fabric is clearer in the unstable case (3D-Rad_v10) than in the neutral case (No-Heat_v10). The implementation of heterogeneous sensible heat flux emphasises the presence of apparent organised turbulent streaky structures. 
(3) Normalised turbulent atmospheric boundary layer

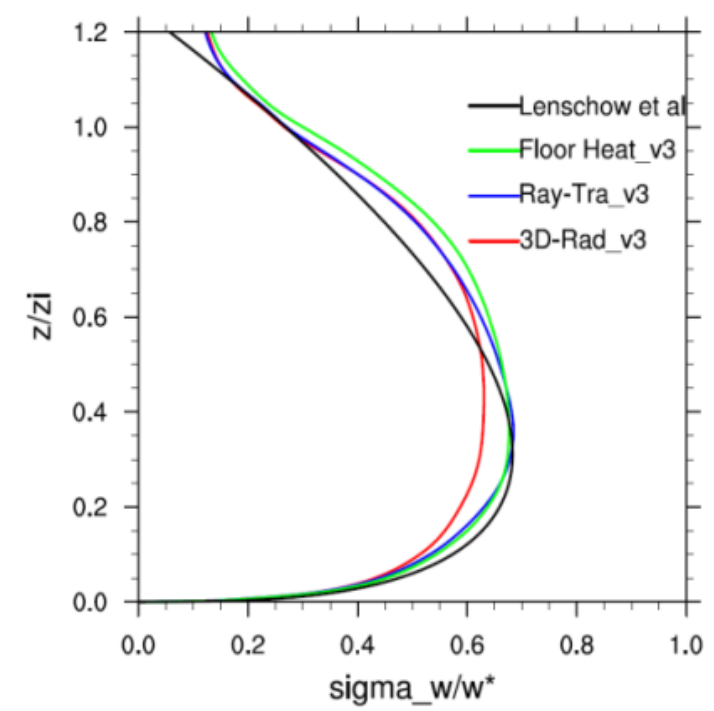

(4) Turbulent field in the atmospheric boundary layer

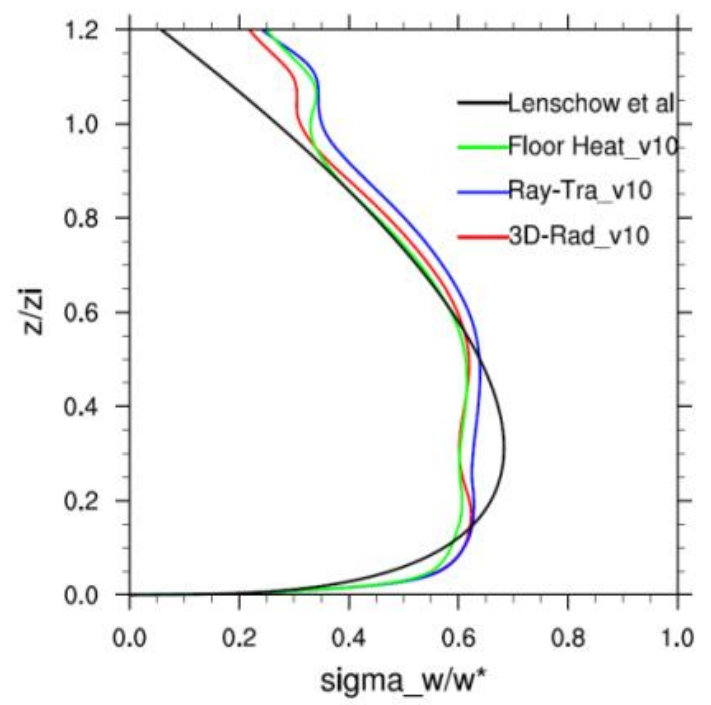

Fig.5 Normalised standard deviation of vertical velocity fluctuations (w) when initial velocity is set to $3 \mathrm{~m} \cdot \mathrm{s}^{-1}$ (left) and $10 \mathrm{~m} \cdot \mathrm{s}^{-1}$ (right).

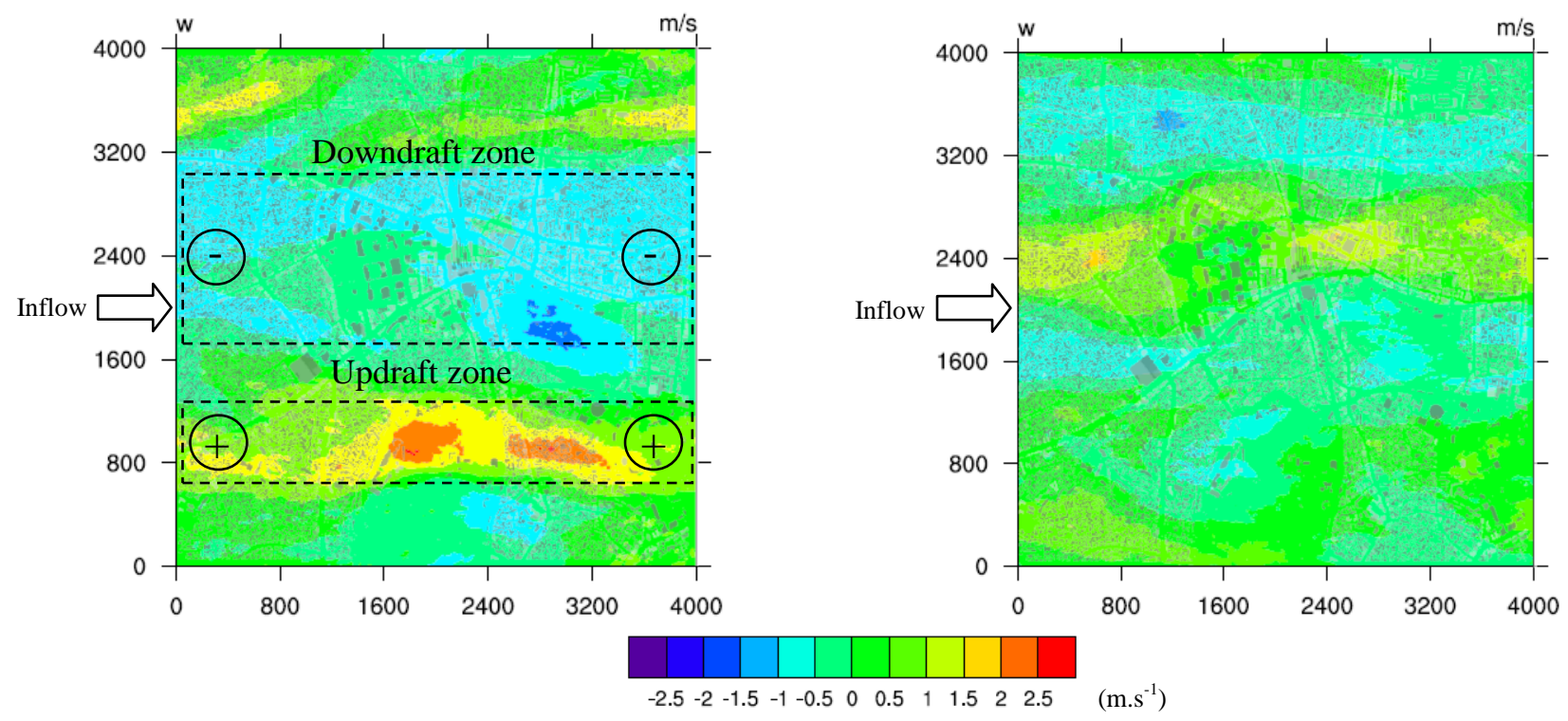

Fig.6 Wind velocity component (w) at $\mathrm{z}=397.5 \mathrm{~m}$ for 3D-Rad_v3 (left,) and Floor-Heat_v3 (right) cases.

Observation data ${ }^{16) 17)}$ by Lenschow et al. has been plotted. In the first set of runs, initial geostrophic wind velocity at the surface (u) was set at $3 \mathrm{~m} \cdot \mathrm{s}^{-1}$. The wind profile is calculated by the PALM 1D model. All runs within this set follow almost similar tendencies with more fluctuations for simulated cases in the convective layer and fewer fluctuations near the surface layer for the simulated heterogeneous heat flux case in terms of normalised standard deviation of vertical velocity (w), see Fig.5. This is probably due to predominant effects of buoyancy. In the second set of runs, initial geostrophic wind velocity at the surface (u) was set at $10 \mathrm{~m} . \mathrm{s}^{-1}$. All runs within this set have calculated two peaks different from observations, see Fig.5. Upper and lower peaks are convection of the boundary layer scale and the strong shear layer respectively.
This section takes into account output results from the case (3D-Rad_v3) where realistic sensible heat flux distributions have been implemented and the case (Floor-Heat_v3) where homogeneous sensible heat flux from urban horizontal surfaces were exclusively implemented, i.e. building roofs and urban ground surfaces. Initial conditions for geostrophic wind velocity at the surface were set at $3 \mathrm{~m} . \mathrm{s}^{-1}$. The calculated distribution of $(\mathrm{w})$ component was outputted at $z=397.5 \mathrm{~m}$, see Fig. 6. This $\mathrm{z}$ value corresponds approximately to more than one and a half times the height of the tallest building. Although both cases have the same values of the total sensible heat flux, more realistic spatial patterns of sensible heat flux led to a more pronounced organised streaky turbulent structure similar to that of a horizontal convective roller. 
As a reminder, Lenschow et al. data has been taken in homogeneous and steady boundary layer (over the ocean) with considerable thermal parcels. This has been achieved through a flight campaign.

\section{CONCLUSION}

The innovation of this numerical method comes from the implementation of the LES model with three-dimensional heterogeneous heat flux from different building geometries similar to real conditions. This allowed the calculation of more pronounced streaky turbulent organized structure due to the localized combined effects of wind shear and buoyancy over urban settlements. Updraft and downdraft momentum has been used as a significant indicator accordingly. This streaky structure includes more intense turbulent mixing over certain regions of the domain and almost certainly indicates the formation of a horizontal convective roll over this district. Only observation data and a few weather models can depict such an event. These rolls are tube-like vortices forced by real surface heating aligned with the mean flow under unstable thermal conditions. Between the rolls either upward or downward motion is forced. This is very useful to prevent local urban weather related-hazards such as heat-cold stresses, pollutant concentrations and gusts. This method can certainly be used for the depiction of other urban meteorology patterns.

If further developed, such high-resolution modelling tools can form a reliable numerical weather prediction model useful to decision-making, meteorology, energy consumption and health issues in urban environments. In this case, the inclusion of the effects related to land cover, building construction materials and three-dimensional urban geometry is essential. However, some challenges regarding computational costs, output results from shorter simulation times, complex modelling, time-consuming approaches and relevance to urban planning might be encountered.

Future research plans might involve the incorporation of realistic thermal effects from diverse land cover distribution in urban areas, more realistic configuration of building construction materials, transparent surfaces and windows, the effects related to ground topography, water and finally the impact from trees and plant canopies.

ACKNOWLEDGMENT: This work was supported by the Japanese Society for the Promotion of Science (JSPS) KAKENHI Grant Numbers 25249066, 26420492 and JSPS research fellowship. Thanks go to the research programme on climate change adaptation fund (RECCA) and to the
TSUBAME supercomputer platform team at Tokyo Institute of Technology for helping to run LES.

\section{REFERENCES}

1) Kanda M., Moriwaki R., Kasamatsu F.: Large eddy simulation of turbulent organized structure within and above explicitly resolved cube arrays. Boundary-Layer Meteorol 112:343-368, 2004.

2) Inagaki A., Kanda M.: Turbulent flow similarity over an array of cubes in near-neutrally stratified atmospheric flow. J Fluid Mech 615:101-120, 2008

3) Coceal, O., Thomas, T.G. \& Belcher, S.E.: Spatial Variability of Flow Statistics within Regular Building Arrays. Boundary-Layer Meteorology, 125(3), pp.537-552, 2007.

4) Solazzo, E. \& Britter, R.E.: Transfer processes in a simulated urban street canyon. Boundary-Layer Meteorology, 124(1), pp.43-60, 2007.

5) Letzel M.O., Krane M., Raasch S.: High resolution urban large-eddy simulation studies from street canyon to neighborhood scale. Atmos Environ 42:8770-8784, 2008.

6) Kanda, M. et al:: A New Aerodynamic Parametrization for Real Urban Surfaces. Boundary-Layer Meteorology, 148(2), pp.357-377, 2013.

7) Castillo, M.C.L., Kanda, M. and Letzel, M.O.: Heat ventilation efficiency of urban surfaces using large-eddy simulation, Annual Journal of Hydraulic Engineering, JSCE, 53, 175-180, 2009.

8) Park, S.B., Baik, J.J., Raasch, S., Letzel, M.O.: A large-eddy simulation study of thermal effects on turbulent flow and dispersion in and above a street canyon. J Appl Meteor Climatol 51: 829-841, 2012.

9) Offerle, B. et al.: Surface heating in relation to air temperature, wind and turbulence in an urban street canyon. Boundary-Layer Meteorology, 122(2), pp.273-292, 2007.

10) Sühring, M. et al.: On the Effect of Surface Heat-Flux Heterogeneities on the Mixed-Layer-Top Entrainment. Boundary-Layer Meteorology, 151(3), pp.531-556, 2014.

11) Yaghoobian, N., Kleissl, J. \& Paw U, K.T.: An Improved Three-Dimensional Simulation of the Diurnally Varying Street-Canyon Flow. Boundary-Layer Meteorology, pp.1-26, 2014.

12) Maronga, B. et al.: The Effect of Surface Heterogeneity on the Structure Parameters of Temperature and Specific Humidity: A Large-Eddy Simulation Case Study for the LITFASS-2003 Experiment. Boundary-Layer Meteorology, pp.1-30, 2014.

13) Raasch S, Schröter S.: A large-eddy simulation model performing on massively parallel computers. Meteorol Z 10:363-372, 2001.

14) Ashie, Y., Kono, T.: Urban-scale CFD analysis in support of a climate sensitive design for the Tokyo Bay area, International Journal of Climatology, Vol.31, pp 174-188, 2011.

15) Bakkali, M., Ashie, Y., Kanda, M., Davies, M \& Steadman, J.P.: 3D-City Irradiance : Outdoor-indoor multi-patch urban energy balance model, the effects of UHI mitigation strategies on building thermal loads over real environments of Tokyo (Under the process of submission to the Energy and Buildings Journal), 2015.

16)Lenschow, D.H., Wyngaard, J.C. \& Pennell, W.T.: Mean-Field and Second-Moment Budgets in a Baroclinic, Convective Boundary Layer. Journal of the Atmospheric Sciences, 37(6), pp.1313-1326, 1980.

17) Lenschow, D.H. \& Stephens, P.L.: The role of thermals in the convective boundary layer. Boundary-Layer Meteorology, 19(4), pp.509-532, 1980.

(Received September 30, 2014) 